\title{
Effective Dispersion of Fullerene with Methacrylate Copolymer in Organic Solvent and Poly(methyl methacrylate)
}

Kohji Yoshinaga*1 , Suguru Motokucho ${ }^{1}$, Ken Kojio ${ }^{1}$, and Akemi Nakai ${ }^{2}$

${ }^{1}$ Ddivision of Chemistry and Materials Science, Faculty of Engineering, Nagasaki University, 14-1 Bunkyo, Nagasaki, Nagasaki 852-8521, Japan

${ }^{2}$ Department of Human Living, Kyushu Women's University, 1-1 Jiyugaoka, Yahatanishi, Kitakyushu, Fukuoka 807-8856, Japan

Corresponding author:

Prof. Kohji Yoshinaga

Division of Chemistry and Materials Science, Faculty of Engineering Nagasaki University

14-1 Bunkyo, Nagasaki, Nagasaki 852-8521, Japan

Phone/Fax: +81-95-819-2650

E-mail: yoshinaga@nagasaki-u.ac.jp 


\begin{abstract}
Dispersion of fullerene, $\mathrm{C}_{60}$, by addition of polymethacrylate dispersant in methyl methacrylate (MMA) and incorporation of $\mathrm{C}_{60}$ into poly(methyl methacrylate) (PMMA) were investigated. Copolymers synthesized by radical copolymerization of MMA and 2-naphthyl methacrylate (NMA), poly(MMA-co-NMA), effectively dispersed $\mathrm{C}_{60}$ in MMA to form clusters of $20 \mathrm{~nm}$. In these cases, addition of minimal 110 naphthyl groups per unit $\mathrm{C}_{60}$ molecule afforded to give clusters of minimum $20 \mathrm{~nm}$ sizes. Furthermore, block copolymers, poly(MMA-b-NMA) with MMA/NMA mole ratio from $12 / 1$ to $20 / 1$, also efficiently dispersed $C_{60}$ to give formation of clusters of $20 \mathrm{~nm}$ size by addition of minimal 40 naphthyl groups per unit $\mathrm{C}_{60}$ molecule, which was corresponding to approximate 9 layers of naphthyl group in block copolymer adsorbed on the surface of the cluster. Hybrid films of $\mathrm{C}_{60} / \mathrm{PMMA}$, prepared by casting of $\mathrm{C}_{60}$-dispersed solution containing PMMA, exhibited absorbance at $400 \mathrm{~nm}$ linearly increased with $\mathrm{C}_{60}$ content.
\end{abstract}

Key words; Fullerene, Polymer dispersant, Polymethacrylates, $\mathrm{C}_{60} / \mathrm{PMMA}$ hybrid film 


\section{Introduction}

Fullerenes have been attractive and highlighted materials due to a spherical $\pi$-conjugated molecule exhibiting characteristic properties, i.e. electron accepting or releasing abilities, high heat conductivity, thermal stability, high refractive index, radical trapping, UV adsorption, and so on. The number of studies has steadily grown covering fundamental to applied fields of science and technology of fullerene chemistry. ${ }^{1-5)}$ Thus, $\mathrm{C}_{60}$ and $\mathrm{C}_{60}$-based nanomaterials have been contributing to a variety of promising applications to protease inhibitors ${ }^{6,7)}$, antibacterial ${ }^{8)}$ and anticancer $^{9)}$ drugs in medicine, high surface area particles and supports in catalysis ${ }^{10)}$, electron carriers in electronic devices ${ }^{1)}$, and semiconductors in solar cells ${ }^{11-13)}$. Meanwhile, since fullerene molecules generally opt to aggregate each other due to strong hydrophobic and/or $\pi-\pi$ interaction between molecules, in most cases of the application, less solubility or dispersion of fullerenes in aqueous or organic solvents usually gives arise to limited utilization ${ }^{2}$. In this respect, the chemical modification via covalent bond has been sometimes conducted to improve solubility or increase affinity with solvents and/or matrixes. The authors have reported that grafting of PMMA onto colloidal silica have improved compatibility with low polar solvents and polymer matrixes in fabrication of periodic particle-arrayed polymer systems by immobilization of colloidal crystals formed by polymer-grafted silica in organic solvent $^{14-16)}$. However, the chemical modifications are mostly complex or inconvenient, but also making $\pi$-conjugation on fullerenes short and sometimes spoil characteristic properties. On the other hand, dispersion of fullerenes employing surfactant, such as surfactant or polymer, is simple and convenient for practical application. Regarding the dispersion utilizing micelles ${ }^{17,18)}$, releasing of surfactant 
from final materials containing fullerenes sometimes makes trouble, especially in the case of electric devices, while polymer dispersants are scarcely leaking out during device processing or assembling due to high molecular weight.

In this study, dispersion of fullerene, $C_{60}$, in methyl methacrylate (MMA) with convenient polymer dispersants, random and block copolymers synthesized by Scheme 1 and 2, and preparation of $\mathrm{C}_{60}$-dispersed PMMA hybrid films were investigated. The reason why polymerzable monomer of MMA was used as a dispersing media was due to supplying for successive bulk radical polymerization for hybridization.

\section{Experimental}

\section{Materials}

Fullerene $\left(\mathrm{C}_{60}\right)$, Nanom purple ST, was purchased from Frontier Carbon Co. Ltd., Japan. MMA, methacryloyl chloride, styrene (St), 2-naphthol, 9-anthracenemethanol, 2,2'-azobis(isobutylonitrile) (AIBN) and organic solvents were obtained from Wako Pure Chemicals. Co., Japan. Poly(methyl methacrylate) (PMMA) of $\mathrm{M}_{\mathrm{n}}=51,000$ and $\mathrm{M}_{\mathrm{w}} / \mathrm{M}_{\mathrm{n}}=2.10$ was synthesized by a conventional radical polymerization in tetrahydrofuran (THF) by AIBN as an initiator.

\section{Measurements}

Number-average of molecular weight $\left(M_{\mathrm{n}}\right)$ and polydispersity index $\left(M_{\mathrm{w}} / M_{\mathrm{n}}\right)$ of the synthesized polymers were determined by a gel permeation chromatography (GPC) on the columns, PL-gel MIXED-C and MIXED-D, Polymer Lab. Co. Ltd., Japan, at $35^{\circ} \mathrm{C}$ using THF as an eluent at the flow rate of $0.8 \mathrm{~mL} / \mathrm{min}$, calibrated with a polystyrene standard. ${ }^{1} \mathrm{H}$ NMR spectra were recorded on a Bruker AVANCE 400 (400 MHz), 
Germany. Sizes of $\mathrm{C}_{60}$ clusters were determined by a dynamic light scattering (DLS) on an Otsuka Electronics DLS-7000 spectrophotometer equipped with a He-Ne laser (10 mW, $633 \mathrm{~nm}$ ), measurable range of which was $3 \mathrm{~nm}$ to $7 \mu \mathrm{m}$. Transmission spectra of hybrid films were recorded on a multichannel spectrometer, Ohtsuka Electronics MCPD-3700, Japan.

\section{Synthesis of monomer}

2-Naphthyl methacrylate (NMA). $\quad$ Into a $50 \mathrm{~mL}$ flask was put a mixture of $0.43 \mathrm{~g}$ (3 mmol) 2-naphthol and $1.95 \mathrm{~mL}(15 \mathrm{mmol}) \quad N, N, N$-triethylamine in $10 \mathrm{~mL}$ dry chloroform, and the solution was cooled on an ice bath. Methacryloyl chloride (0.9 $\mathrm{mL}(9 \mathrm{mmol})$ ) was slowly poured into the solution, and resultant solution was stirred at room temperature for $3 \mathrm{~h}$. Extraction with chloroform from $4 \%$ sodium dicarbonate aqueous solution, and evaporation gave 0.53 g 2-naphthyl methacrylate. ${ }^{1} \mathrm{H}$ NMR $\left(\mathrm{CDCl}_{3}\right): 2.1(3 \mathrm{H}, \mathrm{s}), 6.1(1 \mathrm{H}, \mathrm{d}), 7.4(1 \mathrm{H}, \mathrm{s}), 7.5-7.6$ 8(2H, m), $7.8(1 \mathrm{H}, \mathrm{d})$, 7.9-8.0 (3H, m) ppm.

9-Anthracenylmethyl metharylate (AMMA). This monomer was synthesized by the same manner as described above in $72 \%$ yield. ${ }^{1} \mathrm{H}$ NMR $\left(\mathrm{CDCl}_{3}\right): 1.9(3 \mathrm{H}, \mathrm{s}), 6.1(1 \mathrm{H}$, d), $7.4(1 \mathrm{H}, \mathrm{s}), 7.5(4 \mathrm{H}, \mathrm{m}), 8.4(2 \mathrm{H}, \mathrm{d}), 8.4(2 \mathrm{H}, \mathrm{d}), 8.5(1 \mathrm{H}, \mathrm{s}) \mathrm{ppm}$.

\section{Synthesis of poly(MMA-co-St)}

A typical run was as follows. A mixture of $2.0 \mathrm{~mL}(17.8 \mathrm{mmol}) \mathrm{MMA}, 0.50 \mathrm{~mL}$ (4.5 mmol) St and $20 \mathrm{mg}$ AIBN and $3 \mathrm{~mL}$ dry THF was put into a $25 \mathrm{~mL}$ flask after purging with $\mathrm{N}_{2}$, and the solution was stirred at $75{ }^{\circ} \mathrm{C}$ for $7 \mathrm{~h}$. The product was precipitated with diethyl ether, and filtration and successive drying under reduced 
pressure gave $1.94 \mathrm{~g}$ poly(MMA-co-St) with $\mathrm{M}_{\mathrm{n}}=21,600$ and $\mathrm{M}_{\mathrm{w}} / \mathrm{M}_{\mathrm{n}}=1.76$. Composition of copolymer, mole ratio $\mathrm{m} / \mathrm{n}=5 / 1$, was determined by ${ }^{1} \mathrm{H}$ NMR spectroscopy. Poly(MMA-co-St)s, poly(MMA-co-NMA)s and poly(MMA-co-AMMA)s were synthesized the same manner as described above. In Table 1, characterizations of poly((MMA-co-NMA)s are shown.

Synthesis of 2-cyano-2-methylpropyl 1-naphthalenecarbodithioate (1)

Into a $100 \mathrm{~mL}$ flask $0.7 \mathrm{~g}(29 \mathrm{mmol})$ magnesium, $2 \mathrm{mg}$ iodine and $5 \mathrm{~mL}$ dry THF were put, and the flask was thoroughly purged with nitrogen. Solution of $2.8 \mathrm{~mL}$ (24 mmol) 1-bromonaphthalene in $5 \mathrm{~mL}$ dry THF was added dropwise to the mixture under nitrogen atmosphere at room temperature, followed by refluxing for $1 \mathrm{~h}$. The reaction mixture was cooled down, and $2.4 \mathrm{~mL}(0.4 \mathrm{mmol})$ carbon disulfide in $5 \mathrm{~mL}$ dry THF, followed by refluxing for $1 \mathrm{~h}$. After addition of $10 \mathrm{~mL} 1 \mathrm{~N} \mathrm{HCl}$ to resulting solution, extraction with $40 \mathrm{~mL}$ chloroform three times and evaporation gave viscous reddish crude product. The product was dissolved in $18 \mathrm{~mL}$ ethyl acetate and $1.7 \mathrm{~mL}$ dimethylsulfoxide, and the solution was stirred at room temperature for $12 \mathrm{~h}$. Evaporation and purification by column chromatography using silica gel with eluent of cyclohexane/toluene/dichloromethane (5/4/1 vol) gave 1. ${ }^{1} \mathrm{H}$ NMR $\left(\mathrm{CDCl}_{3}\right): 1.9(6 \mathrm{H}$, s), $7.5(4 \mathrm{H}, \mathrm{m}), 7.9$ (2H, m), $8.1(1 \mathrm{H}, \mathrm{s}) \mathrm{ppm}$.

Synthesis of 1-naphthylcarbodithioate-terminated poly(NMA)(2)

A typical run was as follows. A mixture of $80 \mathrm{mg}(0.27 \mathrm{mmol})$ 1, $1.0 \mathrm{~g}(4.5 \mathrm{mmol})$ NMA and $2.0 \mathrm{~mL}$ benzene was put into a test tube, followed by degassing by freezing and thawing method under vacuum and by purging with nitrogen. After sealing, the 
tube was irradiated by a high pressure Hg lump (500 W) at room temperature for $8 \mathrm{~h}$. Resulting polymer was precipitated with methanol, and then drying under reduced pressure gave $0.21 \mathrm{~g}$ 1-naphthylcarbodithioate-terminated poly(NMA), 2, with $\mathrm{M}_{\mathrm{n}}=3,400$ and $\mathrm{M}_{\mathrm{w}} / \mathrm{M}_{\mathrm{n}}=1.10$.

\section{Synthesis of poly(MMA-b-NMA)}

A mixture of $30 \mathrm{mg}(0.009 \mathrm{mmol})$ 2, $0.80 \mathrm{~mL}$ (7.5 mmol) MMA and $1.2 \mathrm{~mL}$ benzene was put into a test tube and the mixture was degassed by freezing and thawing under vacuum, followed by purging with nitrogen. The polymerization was carried out by irradiation of a high pressure Hg lump. Precipitation with diethyl ether gave $0.53 \mathrm{~g}$ poly(MMA- $b$-NMA) with $\mathrm{M}_{\mathrm{n}}=14,000$ and $\mathrm{M}_{\mathrm{w}} / \mathrm{M}_{\mathrm{n}}=1.35$. In Table 1, Characterizations of poly(MMA-b-NMA)s are also shown.

\section{Dispersion of $C_{60}$}

MMA solution $1.50 \mathrm{~mL}$ of polymer dispersant $(7.0-120 \mathrm{mg}) / \mathrm{mL}$ was added to solution of $1.50 \mathrm{~mL}$ MMA containing $0.28 \mathrm{mg} \mathrm{C}_{60}$. After the MMA solution was sonicated for $5 \mathrm{~h}$ at room temperature, sizes of $\mathrm{C}_{60}$ clusters in the solution were determined by DLS.

Preparation of $C_{60}$-dispersed PMMA films

MMA solution $1.50 \mathrm{~mL}$ containing $36 \mathrm{mg}$ poly(MMA- $b$-NMA) (m/n ratio=20/1) was mixed with $1.50 \mathrm{~mL}$ MMA solution of $0.187 \mathrm{mg} / \mathrm{mL} \mathrm{C}_{60}$. After sonication of the mixture for $3 \mathrm{~h}, 0-0.80 \mathrm{~mL}$ of the mixture was put into $1.50 \mathrm{~mL}$ MMA solution of 80.0 mg/mL PMMA. The solution $(0.50 \mathrm{~mL})$ was casted on a cover glass and dried under 
atmosphere to obtained PMMA film.

\section{Results and discussion}

\section{Effects of ester group in polymethacrylate on dispersion}

Since fullerenes are slightly dissolved in aromatic solvents, such as benzene and toluene, we have examined dispersibility of $\mathrm{C}_{60}$ using polymethacylates consisted of aryl group in MMA. In Table 2, cluster sizes of $\mathrm{C}_{60}$ dispersed with PMMA, poly(MMA-co-St), poly(MMA-co-NMA), and poly(MMA-co-AMMA) are shown. Dispersant polymers, PMMA and poly(MMA-co-St), gave large clusters of $330 \mathrm{~nm}$ and 160 220 nm, respectively. Copolymers consisted of naphthyl and anthracenyl group, poly(MMA-co-NMA) and poly(MMA-co-AMMA), effectively dispersed $\mathrm{C}_{60}$ to form clusters of smaller size in the range from $40 \mathrm{~nm}$ to $50 \mathrm{~nm}$ than those with PMMA and poly(MMA-co-St). From these results, it was clearly showed that naphthyl or anthracenyl group played significant roles in dispersion through $\pi$ - $\pi$ interaction between $\mathrm{C}_{60}$ and the dispersant. Thus, we investigated effects of naphthyl content in poly(MMA-co-NMA) on $\mathrm{C}_{60}$ dispersion in MMA. In Fig. 1, relation of $\mathrm{C}_{60}$ cluster size in MMA using poly(MMA-co-NMA) with different naphthyl content as a function of polymer addition is shown. In dispersion of $0.28 \mathrm{mg}$ fullerene in $3 \mathrm{~mL}$ MMA, addition of high naphthyl-contained copolymers of mole ratio MMA/NMM=2/1 9/1 over $40 \mathrm{mg}$ effectively dispersed $\mathrm{C}_{60}$ to give the cluster of around $20 \mathrm{~nm}$. However, much amount of copolymer of MMA/NMA mole ratio=15/1 and 30/1 was required to give the minimal size of the clusters. Regarding cluster formation, since copolymer aggregates of $10-13 \mathrm{~nm}$ in size in MMA solution of poly(MMA-co-NMA)(mole ratio MMA/NMA=9/1) in the concentration range from 0.5 to $5.0 \mathrm{wt} \%$ without $\mathrm{C}_{60}$ were 
observed, it was confirmed that the clusters were consisted of agglomerates of $\mathrm{C}_{60}$ and polymer dispersants In Fig. 1(b), relation between added naphthyl groups in poly(MMA-co-NMA) and the cluster size is shown. The addition of naphthyl groups over $45 \mu \mathrm{mol}$ in dispersion of $3.75 \times 10^{-1} \mu \mathrm{mol} \mathrm{C}_{60}$ in $3.0 \mathrm{~mL}$ afforded $20 \mathrm{~nm}$ clusters, corresponding to 110 naphthyl groups per unit $\mathrm{C}_{60}$ molecule.

\section{Dispersion with block copolymer dispersant}

In practical application, an important factor is to achieve to disperse $\mathrm{C}_{60}$ with polymer dispersant as small addition as possible. The key factor of the dispersion is not only $\pi-\pi$ interaction between naphthyl group and $\mathrm{C}_{60}$, but also interaction between PMMA moiety of poly(MMA-co-NMA) and MMA solvent (Fig. 2). Therefore, in order to achieve efficient dispersion, we examined block copolymer, poly(MMA- $b$-NMA), having abilities of simultaneous interactions both between naphthyl groups and $\mathrm{C}_{60}$ and between PMMA moiety and MMA, as illustrated in Fig. 2. In Fig. 3, cluster sizes in the dispersion of $\mathrm{C}_{60}$ in MMA using poly(MMA- $b$-NMA), in the range of MMM/NMA mole ratio from $12 / 1$ to $20 / 1$, as a function of polymer addition are shown. In these cases, minimum amounts of polymer addition to give $20 \mathrm{~nm}$ cluster were in the range from 15 to $31 \mathrm{mg}$, which were obviously less amounts than those in dispersion of $\mathrm{C}_{60}$ employing poly(MMA-co-NMA) (Fig. 3(a)). In Fig. 3(b), plots of naphthyl groups added vs. cluster size are also shown. Addition of $15 \mu \mathrm{mol}$ naphthyl groups in block copolymer to suspension of $3.75 \times 10^{-1} \mu \mathrm{mol}_{60}$ in $3.0 \mathrm{~mL}$ MMA gave minimal cluster size of $20 \mathrm{~nm}$, volume of which was corresponding to including $2.01 \times 10^{3} \mathrm{C}_{60}$ molecules on assumption of closed packing. This result showed minimal 40 naphthyl groups per $\mathrm{C}_{60}$ molecule were required to disperse in $3.0 \mathrm{~mL}$ MMA. Otherwise, if 
naphthyl groups would cover surface of $20 \mathrm{~nm}$ spherical cluster in diameter, $8.0 \times 10^{4}$ naphthyl groups/cluster, that was 64 naphthyl groups $/ \mathrm{nm}^{2}$ could be required to disperse. The total area of 64 naphthyl groups is corresponding to $9.0 \mathrm{~nm}^{2}$, on assuming cross sectional area of naphthyl group was $0.14 \mathrm{~nm}^{2}$ evaluated from long sides of naphthyl group, $0.43 \mathrm{~nm}$. Therefore, approximately 9 layers of naphthyl groups might contribute to dispersion of $\mathrm{C}_{60}$ to form $20 \mathrm{~nm}$ clusters in MMA. Unfortunately, in the present technique, it was impossible to make cluster size less than $20 \mathrm{~nm}$ small, which was possibly minimal size of agglomerates, obtained using dispersant, due to strong cohesion force among $\mathrm{C}_{60}$ molecules. In this respect, Balavin et al. ${ }^{19)}$ reported that calculations predicted the formation of stable clusters in highly diluted toluene solution with the smallest cluster containing $13 \mathrm{C}_{60}$ molecules and the largest with 55 molecules.

In dispersion of $\mathrm{C}_{60}$ in MMA employing poly(MMA-b-NMA), therefore, it is suggested that poly(MMA) and poly(NMA) moieties of the block copolymer make effective interaction with $\pi$-conjugation system of $\mathrm{C}_{60}$ and MMA solvent, respectively, to give rise to effective dispersibility of block copolymer, as presented in Fig. 2.

\section{$C_{60} /$ PMMA hybrid film}

In order to evaluate dispersion abilities of poly(MMA- $b$-NMA), fabrication of $\mathrm{C}_{60} / \mathrm{PMMA}$ hybrid films by UV-irradiated radical polymerization of $\mathrm{C}_{60}$-dispersed MMA by using 2,2'-azobis(isobutyronitrile) as an initiator was carried out. However, it was difficult to prepare homogeneously $\mathrm{C}_{60}$-dispersed films of $1 \mathrm{~mm}$ in thickness, because of heterogeneous polymerization in a reaction cell. Hence, fabrication of the hybrid films was examined by a casting method using $\mathrm{C}_{60}$-dispersed and PMMA-dissolved MMA solution to obtain the films. Transmission spectra of the 
films of $60 \mu \mathrm{m}$ in thickness along with photograph, and absorbance at $400 \mathrm{~nm}$ are shown in Fig. 4 and Fig. 5, respectively. Hybrid films of $\mathrm{C}_{60} / \mathrm{PMMA}$ exhibited high transparency to give high transmittance over $90 \%$ at in the range of $450-650 \mathrm{~nm}$. However, transmittance in the visible region increased with increasing $C_{60}$ content. Since $\mathrm{C}_{60}$ and PMMA scarcely have absorption in the region, the decrease of transmittance probably comes from partial aggregation of $C_{60}$ to give clusters over 20 nm. From the fact that absorbance of the hybrid film at $400 \mathrm{~nm}$ linearly increased with $\mathrm{C}_{60}$ content (Fig. 5), it was suggested that $\mathrm{C}_{60}$ homogeneously relatively dispersed in PMMA matrix.

\section{Conclusions}

Dispersion of $\mathrm{C}_{60}$ employing polymethacrylate dispersants in MMA was investigated. Copolymers of MMA and NMA showed effective dispersion of $\mathrm{C}_{60}$. In dispersion of $\mathrm{C}_{60}$ by poly(MMA-co-NMA)s with mole ratio of MMA/NMA=6/1 to 30/1, addition of minimal 110 naphthy groups per unit $\mathrm{C}_{60}$ molecule showed dispersion to give cluster of $20 \mathrm{~nm}$ in diameter. Furthermore, block copolymers, poly(MMA-b-NMA)s with MMA/NMA mole ratio from $12 / 1$ to $20 / 1$, also exhibited effective dispersion of $\mathrm{C}_{60}$ to give clusters of $20 \mathrm{~nm}$ size by addition of minimum 40 naphthyl groups per $\mathrm{C}_{60}$ molecule, corresponding to approximately 9 layers of naphthyl groups adsorbed on the cluster. Hybrid films prepared by $\mathrm{C}_{60}$-dispersed MMA solution using poly(MMA-b-NMA) showed high transparency, and absorbance of the films at $400 \mathrm{~nm}$ linearly increased with $\mathrm{C}_{60}$ content.

\section{References}


1. Bonifazi D, Enger D, Diedrich F (2007) Chem Soc Rev:390

2. Patnaik A (2007) J Nanosci Nanotech 7:111

3. Darwish AD (2009) Ann Rep Prog Chem:363

4. Ravi P, Dai S, Wang C, Tam KC, J Nanosci Nanotech 7:1176

5. M-Alonso A, Guldi DM, Paolucci F, Prato M, Angew Chem Int Ed 46:8120

6. Tanimoto S, Sakai S, Matsumura S, Takahashi D, Toshima K (2008) Chem Commun:5767

7. Durdagi S, Mavromoustakos T, hronakis N, Papadopoulos MG (2008) Bioorg Med Chem 16:9957

8. Spesia MB, Milanesio AE, Durantini EN (2008) Eur Med Chem 43:1215

9. Akiyama M, Ikeda A, Shintani T, Doi Y, Kikuchi J, Ogawa T, Yogo K, Takeya T, Yamamoto N (2008) Org Biomol Chem 6:1015

10. Dresselhaus MS, Dresehaus G, Eklund PC, Science of Fulerenes and Carbon Nanotubes, Academic Press, San Diego (1996).

11. Jiang HJ, Deng XY, Dendzik W (2008) 36:390

12. Lee JK, Ma WL, Brabec CJ, Yuen J, Moon JS, Kim JY, Lee K, Bazan GC, Heeger AJ (2008) 130:3619

13. Fernandez G, Sanchez L, Veldman D, Wienk MM, Atienza C, Guldi DM, Janssen RAJ, Martin N (2008) J Org Chem 73:3189

14. Yoshinaga K, Chiyoda M, Ishiki H, Okubo T (2002) Colloids Surf A 204:285

15. Yoshinaga K, Fijiwara K, Mouri E, Ishii M, Nakamura H (2005) Langmuir 21:4471

16. Ma Z, Watanabe M, Mouri E, Nakai A, Yoshinaga K (2011) colloid Polym Sci 289:85

17. Bensasson RV, Bienvenue E, Dellingers M Leach S, Seta P (1994) J Phys Chem 
$98: 3492$

18. Raston CL, Atwood JL, Nichols PJ, Sudria (1996) Chem Commun 2615

19. Bulavin LA, Adamenko II, Yashchuk VM, Ogul’chansky TY, Prylutsky YI, Durov SS, Scharff P (2001) J Mol Liquids 93:187 
Table 1. Characterizations of poly(MMA-co-NMA) and poly(MMA-b-NMA)

\begin{tabular}{lccc}
\hline \multicolumn{1}{c}{ Polymer } & $\begin{array}{c}\text { Mole ratio } \\
\mathrm{m} / \mathrm{n}\end{array}$ & $\begin{array}{c}\mathrm{M}_{\mathrm{n}} \\
/ 10^{3}\end{array}$ & $\mathrm{M}_{\mathrm{w}} / \mathrm{M}_{\mathrm{n}}$ \\
\hline & $2 / 1$ & 12.3 & 1.90 \\
& $6 / 1$ & 10.4 & 2.20 \\
poly(MMA-co- & $7 / 1$ & 26.0 & 1.60 \\
NMM) & $9 / 1$ & 11.5 & 1.78 \\
& $15 / 1$ & 14.5 & 1.89 \\
& $30 / 1$ & 25.0 & 2.45 \\
$\ldots$ & $12 / 1$ & 10.0 & 1.29 \\
poly(MMA- $b-$ & $16 / 1$ & 12.0 & 1.34 \\
NMA) & $20 / 1$ & 14.0 & 1.35 \\
\hline
\end{tabular}


Table 2. Effects of copolymer component on fullerene dispersion in MMA ${ }^{\text {a) }}$

\begin{tabular}{|c|c|c|c|}
\hline Copolymer & $\begin{array}{l}\mathrm{M}_{\mathrm{n}} \\
/ 10^{3}\end{array}$ & $\begin{array}{l}\text { Mole ratio } \\
\mathrm{m} / \mathrm{n}^{\mathrm{b})}\end{array}$ & $\begin{array}{l}\text { Cluster size } \\
\text { / nm }\end{array}$ \\
\hline PMMA & 51.5 & -- & $330 \pm 62$ \\
\hline \multirow{2}{*}{ poly (MMA-co-St) } & 27.8 & $5 / 1$ & $160 \pm 31$ \\
\hline & 22.2 & $9 / 1$ & $200 \pm 42$ \\
\hline \multirow[t]{2}{*}{ poly(MMA- $c o$-NMA) } & 96.0 & $7 / 1$ & $42 \pm 12$ \\
\hline & 5.3 & $9 / 1$ & $57 \pm 14$ \\
\hline poly(MMA- $c o$-AMMA) & 3.0 & $11 / 1$ & $52 \pm 16$ \\
\hline
\end{tabular}


Figure captions:

Scheme 1. Synthesis of methacrylate copolymers by radical polymerization.

Scheme 2. Synthesis of poly(MMA-b-NMA).

Fig. 1. Dependence of $\quad \mathrm{C}_{60}$ cluster size on poly(MMA-co-NMA) addition (a) and naphthyl group (b).

Fig. 2. Schematic representation of interaction between $\mathrm{C}_{60}$ cluster and poly(MMA-co-NMA) (a) or poly(MMA-b-NMA) (b).

Fig. 3. Dependence of $\mathrm{C}_{60}$ cluster size on poly(MMA-b-NMA) addition (a) and naphthyl group (b).

Fig. 4. Transmission spectra of $\mathrm{C}_{60} / \mathrm{PMMA}$ hybrid films $(60 \mu \mathrm{m})$, prepared with poly(MMA- $b$-NMA) $(\mathrm{m} / \mathrm{n}$ ratio=20/1).

Fig. 5. Changes of absorbance of $\mathrm{C}_{60}$ hybrid films at $400 \mathrm{~nm}$ with $\mathrm{C}_{60}$ content. 


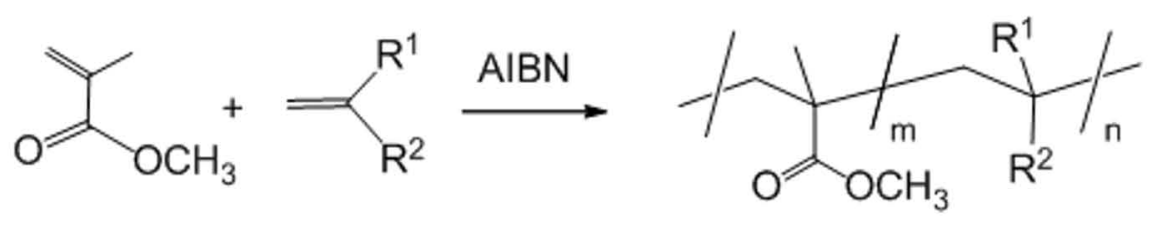

Poly(MMA-co-St): $\mathrm{R}^{1}=\mathrm{H}, \mathrm{R}^{2}=\longrightarrow$

Poly(MMA-co-NMA): $\mathrm{R}^{1}=\mathrm{CH}_{3}, \mathrm{R}^{2}=$

Poly(MMA-co-AMMA): $\mathrm{R}^{1}=\mathrm{CH}_{3}, \mathrm{R}^{2}=$

Scheme 1 . Synthesis of methacrylate copolymers by radical polymerization. 

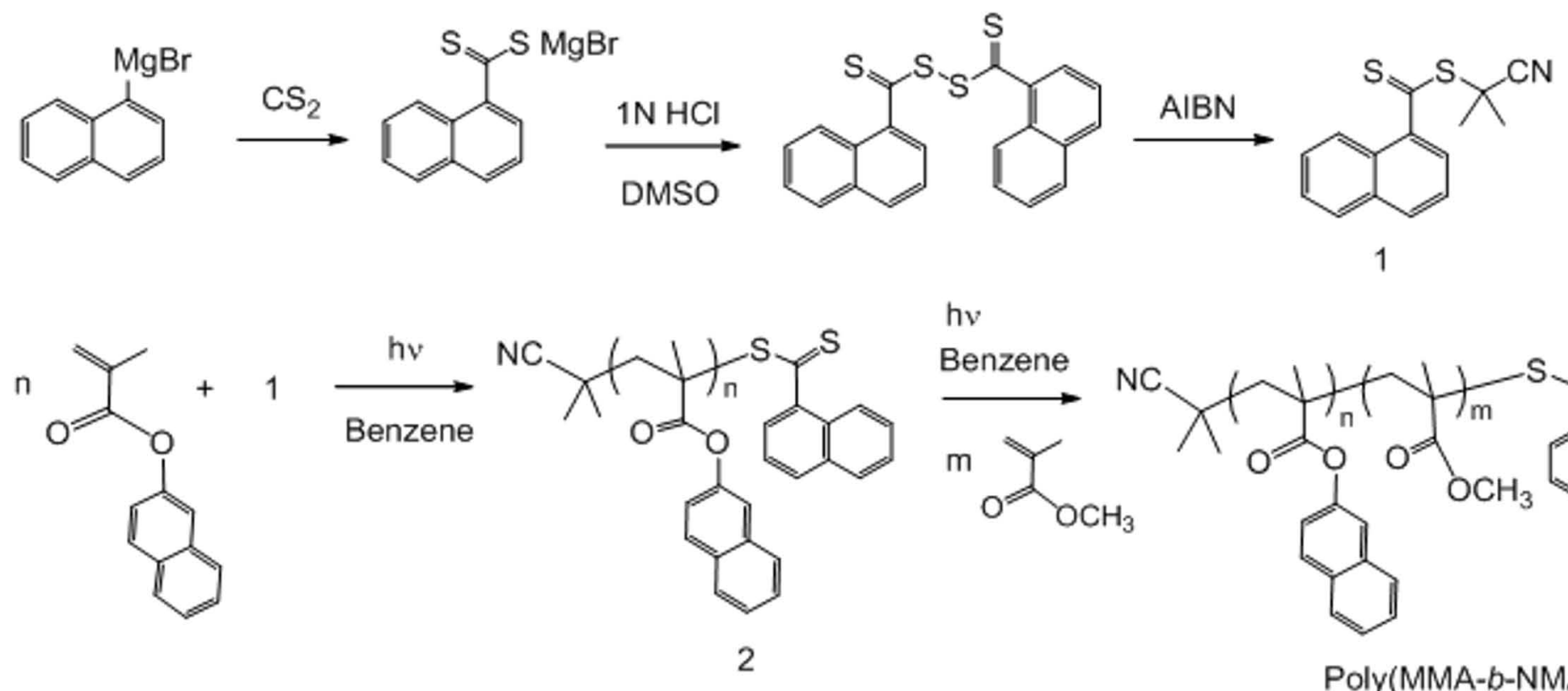

hv

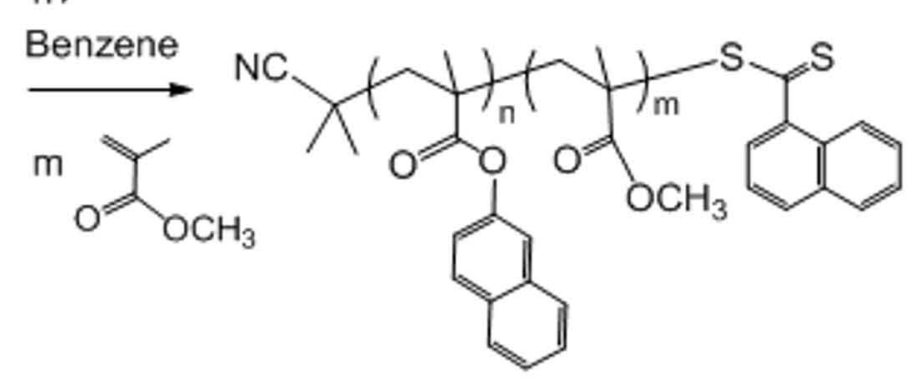

Poly(MMA-b-NMA)

Scheme 2. Synthesis of poly(MMA-b-NMA). 

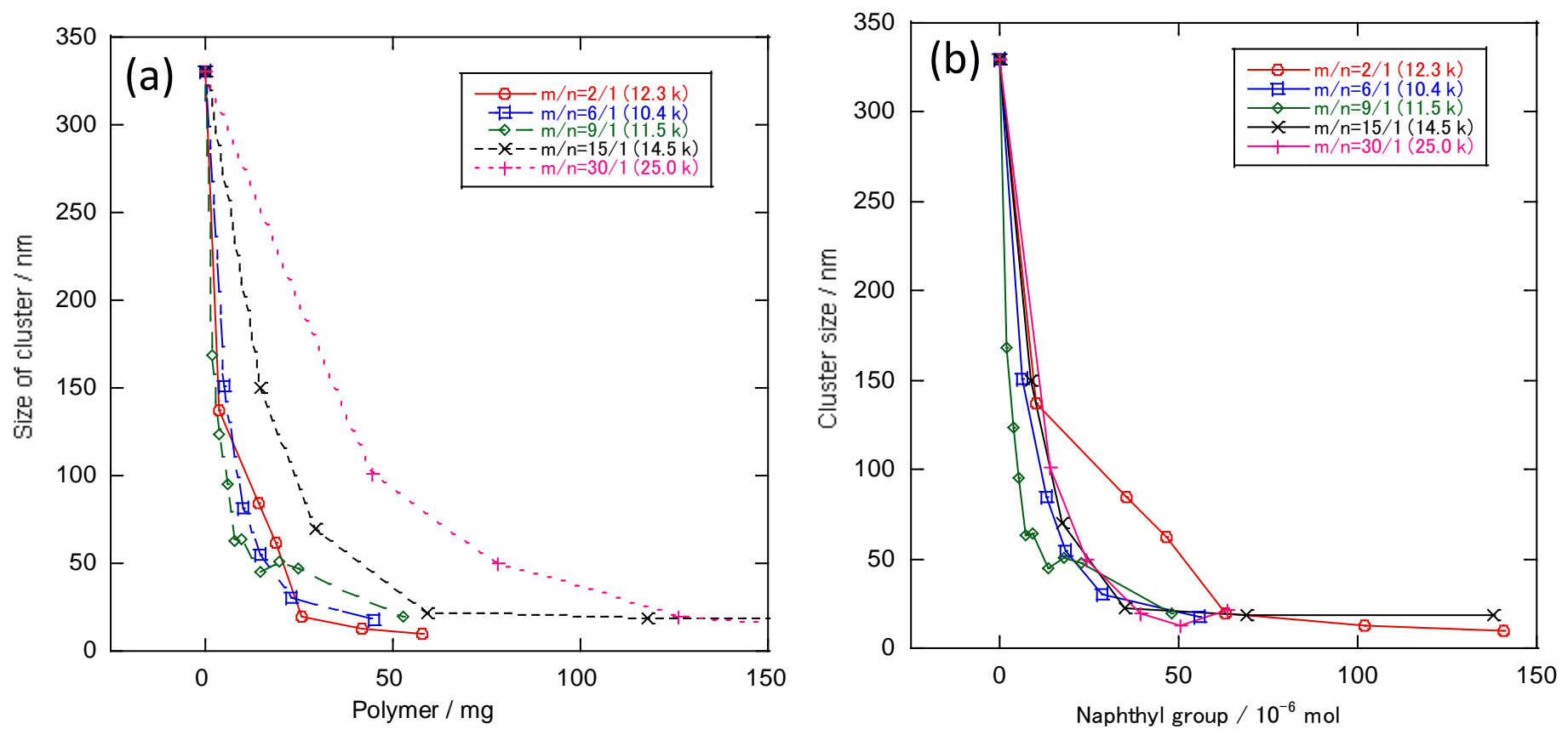

Fig. 1. Dependence of $\mathrm{C}_{60}$ cluster size on poly(MMA-co-NMA) addition (a) and naphthyl group (b). 
(a)

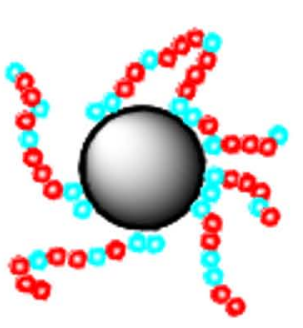

(b)

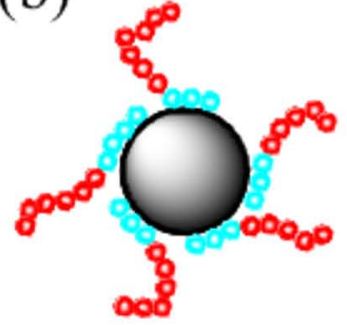

Fig. 2. Schematic representation of interaction between C60 cluster and poly(MMA-co-NMA) (a) or poly(MMA-b-NMA) (b). 

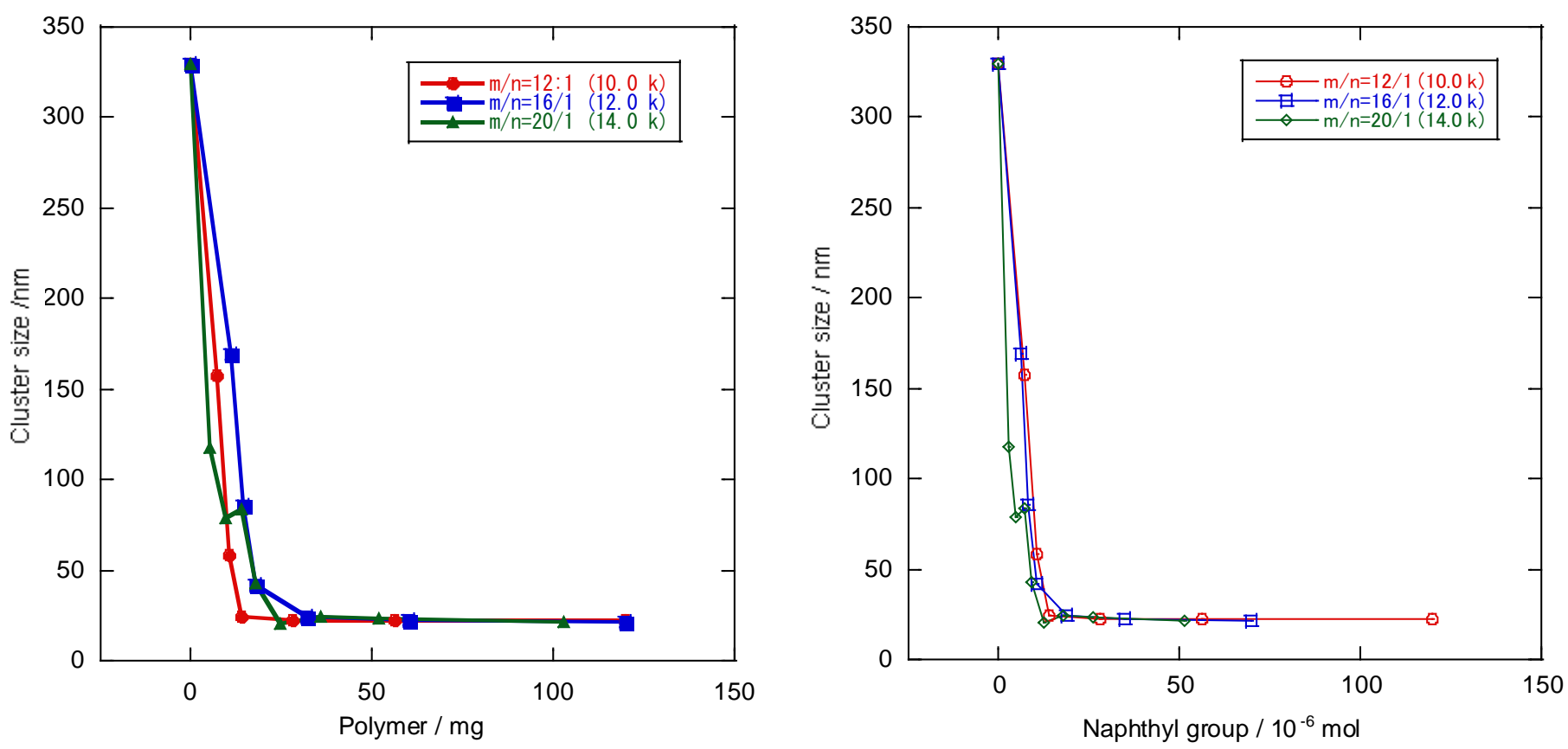

Fig. 3. Dependence of $C_{60}$ cluster size on poly(MMA-b-NMA) addition (a) and naphthyl group (b). 


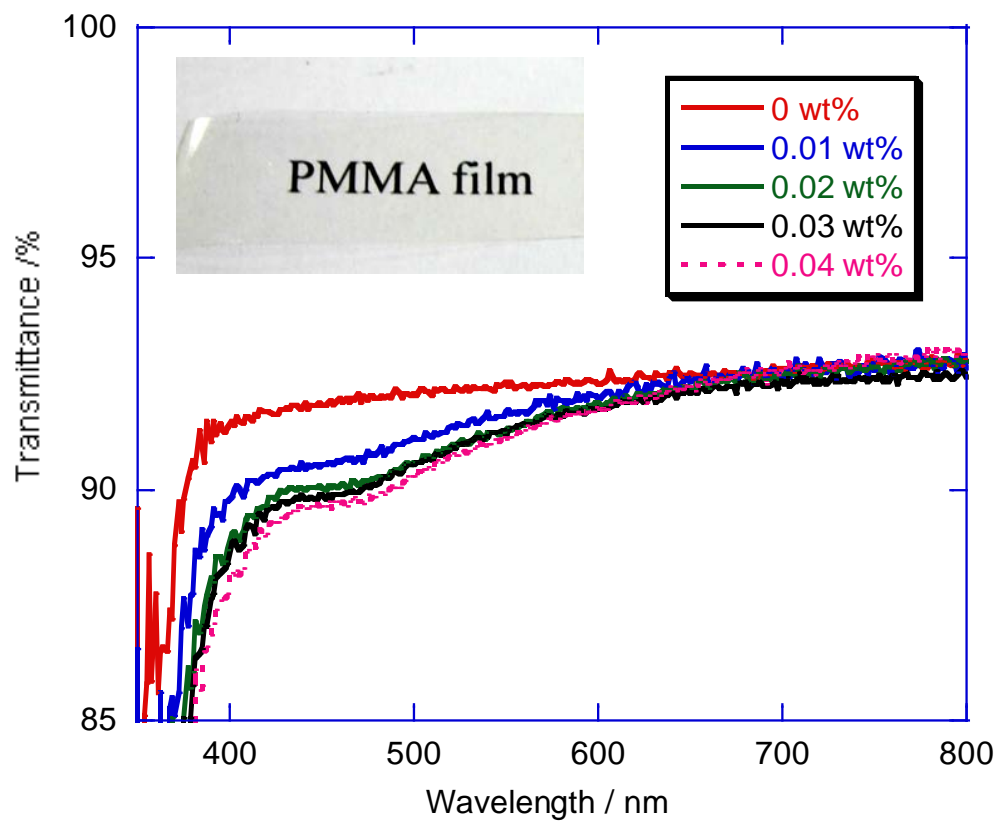

Fig. 4. Transmission spectra of $\mathrm{C}_{60} / \mathrm{PMMA}$ hybrid films $(60 \mu \mathrm{m})$, Prepared with poly(MMA-b-NMA) (m/n ratio=20/1). 


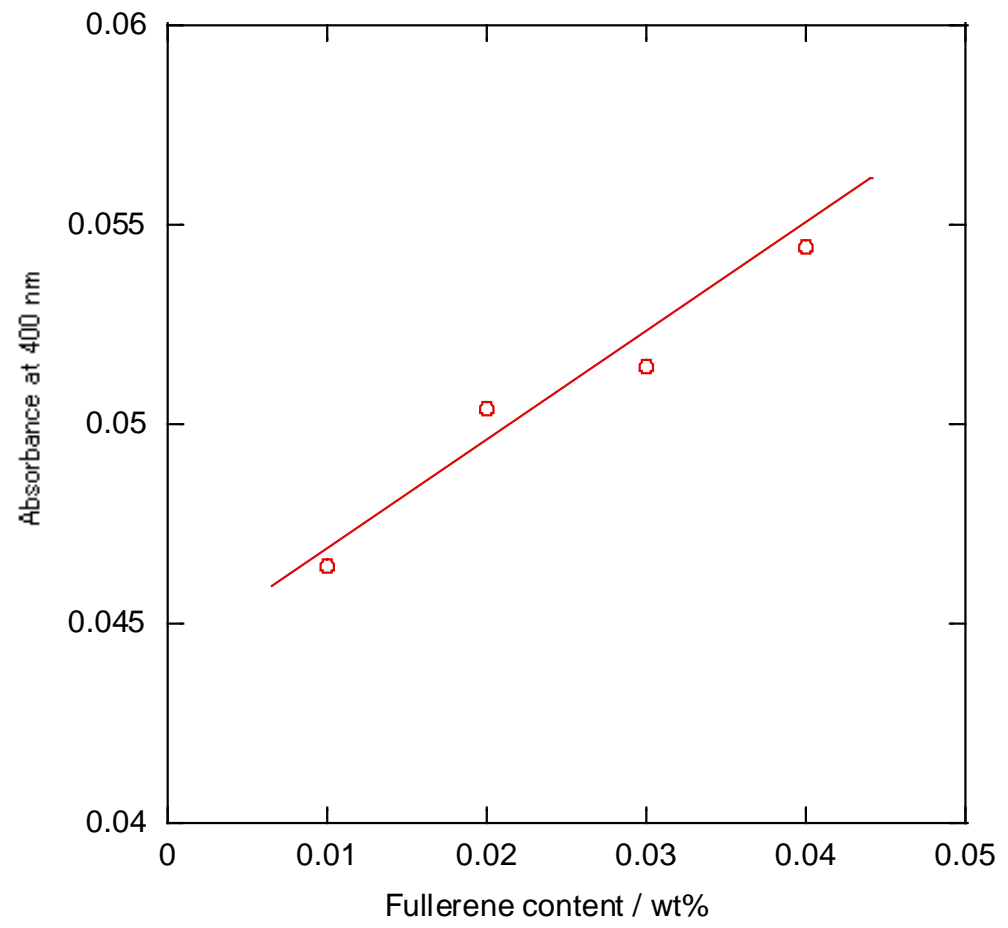

Fig. 5. Changes of absorbance of $\mathrm{C}_{60}$ hybrid films at $400 \mathrm{~nm}$ with $\mathrm{C}_{60}$ content. 